\title{
Os impérios de mídia no estágio da oligopolização
}

\author{
Dênis de Moraes \\ UFF
}

Quando o poder está oscilando entre diferentes partes da cadeia de valor, você precisa deter toda a cadeia.

Dick Parsons, presidente da Time Warner.'

\section{Os novos comandos estratégicos}

A formação de oligopólios constitui o eixo preponderante do atual modelo organizacional das corporações de mídia e entretenimento. As empresas com especializações únicas definham. Elas correspondiam a um outro espaço-tempo, em que as tecnologias não encurtavam mapas, calendários e fusos horários; os fluxos de informações eram infinitamente menos convulsivos; e não vigorava o mandamento competitivo de gerar demandas em mercados de abrangência ilimitada. $O$ equilíbrio de forças alterou-se por completo. Esta é a era dos conglomerados multimídias, estruturados para exercer hegemonia em todas as pontas da revolução digital.

A oligopolização insere-se no painel de forte concentração de comandos estratégicos e de mundialização de conteúdos, mercadorias e serviços, facilitada pelas desregulamentações, pela supressão de barreiras fiscais, pela acumulação de capital nos países industrializados, pela deslocalização das bases de produção e, evidentemente, por redes tecnológicas de múltiplos usos. Na base da chamada "flexibilização dos investimentos empresariais" - eufemismo para o processo de concentração multinacionalizada de bens e serviços - a realização de lucros implica maior acumulação de capital ao menor custo possivel. O que 
pressupõe: a) amplos mercados consumidores; b) concorrência intensa entre um número cada vez menor de megagrupos, graças a fusões e irłcorporações; c) centralização das decisões fundamentais e dos planos de inovação nas matrizes dos grupos transnacionais, com que também supervisionam as operações no exterior.

Os blocos interempresariais buscam competir em posição de força. Os acordos mesclam estoques de munição financeira e know-how tecnológico que nenhuma firma, isoladamente, teria condições de mobilizar e garantir. A opção por joint ventures traduz o propósito de diluir os aportes financeiros entre os participantes, reduzindo as margens de risco. Trata-se da aplicação de capitais em investimentos industriais de longo alcance geográfico, com expectativa de polpudos retornos em função da economia de escala. Lester Turrow alude ao fenômeno das "familias tecnológicas": elas evoluem de um produto a outro com tamanha rapidez que quase não sobram chances, para firmas ainda fora do ramo, de nele entrarem em condições reais de competitividade. ${ }^{2}$ As companhias de médio porte que não se vinculam a conglomerados ou não descobrem nichos rentáveis estão condenadas a desaparecer. Estudo da consultoria norte-americana McKinsey sobre fusões e alianças conclui que a competição mundial nos próximos anos tende a envolver apenas cinco grandes empresas por setor. "Estamos em meio a uma corrida para ver quem sobreviverá", diz Heinz-Peter Elstrodt, sócio da McKinsey. ${ }^{3}$ Raj Sisodia, professor de marketing da George Mason University, é taxativo: "Numa economia madura, três companhias gigantes, invariavelmente, acabam com 70\% do mercado." E cita exemplos: McDonald's, Burger King e Wendy dominam o fast-food; Nike, Adidas e Reebok são as maiorais dos tênis; Michelin, Goodyear e Bridgestone dão as cartas nos pneus. ${ }^{4}$

As pretensões de auto-suficiência desfazem-se diante da exigência de vultosos recursos para sustentar a capacitação tecnológica, a diversificação produtiva, a pesquisa sistemática, a acirrada concorrência em mercados internacionalizados e o marketing global. Estes itens requerem integração de circuitos e equipamentos, de métodos de gestão e de interconexões de sistemas operativos. Fusões e parcerias deixam entrever perspectivas para o intercâmbio e o acréscimo de competências gerenciais e especializações produtivas. É a interpenetração de aparatos tecnológicos, com valor-de-uso complementar, que introduz circunstâncias e fatores sinergéticos. Os conglomerados formalizam estratégias de 
cooperação, explicitadas em alianças nacionais ou transnacionais. René Armand Dreifuss salienta que as conglomerações e sinergias transcendem a busca de conhecimento inovador e se fixam no seu entorno: "Elas procuram alcançar a magnitude e qualidade dos recursos (humanos, materiais e de infra-estrutura social) necessários à pesquisa e para assegurar condições de produção (incluindo o controle de componentes e insumos), já que, a cada nova geração, os custos sobem de forma geométrica, enquanto cresce a complexidade do processo e do produto. São razões, mais do que suficientes, para estabelecer alianças que objetivam reduzir, partilhar e distribuir custos e perdas (e minimizar riscos) na pesquisa científica e na sua "tradução" tecnológica, no desenho de projeto, no desenvolvimento de novos produtos (...) e na produção de produtos de ponta."s

As alianças podem ser de curta ou longa duração ou duradoura, conforme o teor de seus objetivos e desdobramentos. O raio de incidência também varia. As alianças transnacionais realizam-se através das fronteiras dos países, entre corporações complementares, suplementares e às vezes concorrentes, com vistas à plena utilização de infra-estruturas e ao aprimoramento das condições de produção e comercialização, estando subjacentes os princípios de redução ou minimização de fatores adversos e de risco. Já as alianças setoriais - que envolvem empresas de diferentes ramos mas com base operacional em um mesmo país - visam ao aproveitamento de interfaces nas áreas de conhecimento e de produção, inclusive entre competidores. ${ }^{\circ}$

As combinações de ativos surgem para viabilizar interesses reciprocos ou conciliáveis, reduzindo o espaço de manobra dos concorrentes. Como esclarece Philippe Natag, diretor-executivo da consultoria Regent Associates: "O mercado de tempo real impele grandes empresas a um movimento para fora de si mesmas, atrás de integração societária. Por outro lado, esta integração não pode mais se circunscrever a blocos regionais; ela precisa se reforçar no plano internacional, se quiser ampliar seus serviços e penetrar fortemente em outros segmentos de mercado."

Foi exatamente o que fizeram as norte-americanas Dow Jones e General Electric (proprietária da rede de TV NBC) ao unificarem suas operações de TV e Internet na Ásia e Europa. Objetivo: minimizar os custos para expansão. O canal a cabo CNBC perdia US\$25 milhões por ano na Ásia e US\$ 15 milhões na Europa. A Dow Jones registrava prejuizo de US\$ 48 milhões por ano em projetos de TV. Com o acordo. a Dow Jones 
vai fundir o Asia Business News e o European Business News com a CNBC. Os novos canais atingirão nove milhões de domicílios na Ásia e 15 milhões na Europa. As empresas poderão fazer marketing cruzado de marcas como o Wall Street Journal e outros serviços de notícias da Dow Jones, o CNBC e o site de informações MSNBC (joint venture entre a NBC e a Microsoft). "A parceria não tornará os canais lucrativos em seis meses, mas eles vão sair do vermelho mais rapidamente", esclareceu Peter Kann, executivo-chefe da Dow Jones. 8

Os complexos industriais administram empreendimentos paralelos ou convergentes, ao mesmo tempo as sinergias evitam disparidades de orçamentos e concatenam suas atividades. Os portfólios podem até variar, mas as corporações seguem variantes comuns para globalizar os bens culturais: confluência tecnológica e internacionalização de mercados. A concentração de capital nessas superestruturas intercambia-se com o contraditório movimento de deslocalização operacional, em face da exigência de extrair rentabilidade no maior número possível de bases consumidoras. Cabe aos pólos de enunciação e difusão harmonizar os elementos aparentemente desconexos - na verdade, partes do sistema cultural global. As unidades locais e regionais subordinam-se à lógica estratégica dos boards corporativos, com autonomia para articular as proposições mercadológicas a especificidades socioculturais.

Efeito colateral da conglomeração e da descentralização da produção em países com mão-de-obra mais barata, acentua-se dramaticamente a redução do nivel de emprego. Os cortes possibilitados pela administração compartilhada e pela otimização tecnoprodutiva determinam enxugamentos de pessoal. Apesar da fase próspera da economia norteamericana, com uma das menores taxas de desemprego da história, crescem as demissões relacionadas à concentração empresarial. Somente em abril de 1998, 50 mil empregos foram ceifados nos EUA, dos quais 17\% em conseqüência de fusões. É o maior nível desde agosto de 1995, quando a reengenharia empresarial foi responsável por quase metade das demissões do mês. A Compaq, maior fabricante mundial de computadores pessoais, já dispensou 5 mil e demitirá outros 12 mil funcionários nas unidades da China, Taiwan, Japão, Austrália, Escócia, Brasil, Canadá e EUA, por conta das absorções da Digital Equipament e da Tadem Computers. Ao todo, a integração corporativa ocasionará uma diminuição de $20 \%$ nos postos de trabalho. A Compaq persegue uma performance capaz de elevar o seu faturamento global, ao mesmo tempo 
em que contém dispêndios nas esferas administrativas." Perspectiva semelhante levou a $\mathrm{MCI}$ WorldCom a cortar 2.500 funcionários (3\% de sua força de trabalho), como parte do plano para reduzir US\$2.5 bithões em despesas em 1999. A meta é eliminar "sobreposição de pessoal" em telefonia local e marketing. ${ }^{10}$ Por conta do acordo anteriormente descrito. Dow Jones e General Electric fecharão 200 vagas na Europa e na Ásia.

Robert Kurz salienta que, para o conjunto do capital social, fusões e incorporações provocam danos. visto que. no cômputo geral, empregos e capital são mais aniquilados do que recriados. "Uma grande parte das incorporaçôes, abstraindo o outsourcing, só serve para tirar proveito da disparidade de custos, ou seja, para fechar setores relativamente dispendiosos da empresa e reabri-los em outras localidades, com encargos tributários e impostos ecológicos menores e salários mais baixos. (...) Mesmo quando as empresas incorporadas continuam a produzir. a fusão é acompanhada, em geral, do surto de racionalização na esfera administrativa: empregos são extintos, setores inteiros da hierarquia são eliminados e filiais fecham suas portas." "

Os parâmetros de rentabilidade às vezes conduzem megafirmas a se desfazer de empresas ou atividades que não mais se compatibilizam aos eixos preferenciais de investimentos. O desmembramento seletivo visa descartar ou reduzir empreendimentos secundários ou fora dos escopos tecnológicos e/ou mercadológicos. Dentro de tal raciocínio, a Viacom negociou com o Pearson a divisão educacional da editora Simon \& Schuster, ficando apenas com a área de ficção. Além de pôr à venda $20 \%$ do capital de suas 173 emissoras de rádio. a CBS repassou. em setembro de 1998, 70\% das ações do canal CBS-Telenoticias ao grupo mexicano Medios de Comunicación (MedCom). O dinheiro arrecadado será investido pela CBS na reestruturação de sua rede de televisão. A News Corporation aceitou os US\$ 2 bilhões e $40 \%$ das açòes oferecidos pela United Video Satellite Group pela revista TV Guide. A News segue disposta a retirar-se do mercado norte-americano de revistas (resta-lhe agora a The Weekly Standard). No caso da TV Guide, pesou a queda na circulação nos últimos dez anos — de 16.3 milhões de exemplares em 1988 para 13 milhões em 1998.

\section{Desregulamentação e hegemonia dos EUA}

A ocupação dos mercados multimidias por gigantes empresariais de- 
lineou-se a partir dos anos 80 , em compasso com as políticas neoliberais da era Margareth Thatcher-Ronald Reagan-Helmut Kohl. A emergência da mídia global ocorre, pois, no ambiente de desregulamentação e privatização, de abertura e internacionalização econômicas sem precedentes e sob a ideologia do mundo sem fronteiras. As megacompanhias tornam-se componentes essenciais na vertiginosa escalada capitalista, no seu duplo movimento de concentração de capital e de descentralização de mercados. A sua inserção na economia global acentuou-se ao longo da década: em 1980, a receita do setor de comunicação somava US\$ 350 bilhões; em 1989, ultrapassava US\$ 1,6 trilhão. Entre os fatores determinantes, devem ser ressaltadas a explosão tecnológica; a reconfiguração das empresas de mídia em conglomerados, com aumento substancial das vendas internacionais, através de acordos e parcerias; a quebra dos monopólios de telecomunicações e a flexibilização da legislação sobre os meios de comunicação nos EUA.

A globalização reforçou enormemente a supremacia das indústrias do entretenimento baseadas nos EUA. O volume de filmes, programas televisivos e videoteipes exportados para a Europa cresceu $225 \%$ entre 1984 e 1988, com receita média anual de US\$ 561 milhões. Das $130 \mathrm{mil}$ horas de programas veiculados na região, somente 25 mil eram produções européias. Mais da metade da programação provinha dos EUA, assim como $60 \%$ dos filmes exibidos. ${ }^{12}$ De 1987 a 1991 , Hollywood dobrou as vendas de filmes e seriados de TV para o exterior, evoluindo 0 faturamento de U\$ 1,1 bilhão para US $\$ 2,2$ bilhões. No mesmo período, as gravadoras norte-americanas duplicaram as suas exportações, num total de US\$ 419 milhões em 1991. Na virada para a década de 1990, CNN International, MTV e ESPN já eram distribuídos em vários continentes. A CNN - que ao entrar no ar em $1^{\circ}$ de junho de 1980 alcançava 1,7 milhão de lares norte-americanos conectados por cabo - chegou a 70 milhões de casas nos EUA e a 91 países, em 1991, na seqüência do êxito de sua cobertura ao vivo, via satélite, da Guerra do Golfo.

Coincidindo com o início da desregulamentação e da desestatização, as novas tecnologias impulsionaram o crescimento das comunicações na América Latina, particularmente entre 1987 e 1991. Os impactos sucederam-se, em gradações diversas, de país para país: aumento considerável do número de emissoras de televisão; lançamentos de satélites domésticos; disseminação das antenas parabólicas; funcionamento de emissoras de TV em UHF; implantação e inserção na redes mundiais de 
transmissão de dados; introdução da televisão por assinatura (a cabo, por satélite e microondas); formação de redes regionais de TV; e importação de equipamentos de telecomunicações e de radiodifusão. $O$ barateamento do uso de satélites e o aumento de demanda por parte das cadeias de TV alargaram o mercado para os centros de produção norteamericanos. Em 1991, os EUA respondiam por $77 \%$ da programação das TVs latino-americanas, exportando 150 mil horas de filmes, seriados, desenhos animados, esportes e variedades.

A passagem dos anos 80 para os 90 traduziu com clareza as duas vertentes que moldariam o desenvolvimento posterior da indústria da comunicação. De um lado, aprofundou-se a oligopolização nos setores de rádio, televisão, cabo, mídia impressa, cinema, vídeo, música e livros. Em 1980, 50 companhias respondiam por $90 \%$ do faturamento com informação e entretenimento; em 1990, menos da metade delas ficava com os mesmos $90 \%$. O encurtamento do mercado agravou-se após a primeira onda de fusões e aquisições de empresas. As principais transações foram as compras da rede NBC pela General Electric e da rede $\mathrm{ABC}$ pelo grupo Capital Cities, ambas em 1986; a fusão da Time Incorporated com a Warner Communications, em 1989; a constituição da cadeia Fox pela News Corporation. aglutinando emissoras independentes, em 1990; as transferências dos controles acionários da Columbia Pictures e da MCA/Universal para as japonesas Sony e Matsushita, réspectivamente, em 1990. (A MCA/Universal foi revendida, em 1995. por US $\$ 5,7$ bilhões, ao grupo canadense Seagram.)

De outro lado, todas as setas levavam a uma aguda internacionalização da midia. seja pelos sinais de saturação do mercado norte-americano, seja pela redução ou pela supressão das barreiras protecionistas na maioria dos países sob influência neoliberal. e notadamente pelo imperativo de remunerar o capital em bases descentralizadas de consumo. O avanço tecnológico em três pontas do processo - a modernização acelerada. a convergência das redes de transmissão e a produção multimídia - conjugou-se à necessidade de escoar extensivamente as programações.

Os anos 90 consolidam o mercado global como mola-mestra do planejamento estratégico das megacompanhias. Para obter diferenciais competitivos. elas assenhoram-se de satélites e cabos. abrem subsidiárias para a coordenação dos investimentos regionais e estabelecem acordos com firmas locais. Sem a segunda onda de fusões e aquisições. tais 
ações dificilmente teriam a amplitude geográfica, a contundência mercadológica e a variedade de fluxos de informação. Abalos sísmicos sucederam-se em 1995, quando as fusões contabilizaram US\$ 1 trilhão. Três setores lideraram os negócios: o sistema bancário e as indústrias farmacêutica e de mídia. Nada menos do que 243 fusões se registraram na área de comunicações nos EUA. A Disney adquiriu a Capital Cities/ ABC por US\$ 19 bilhões; a Westinghouse comprou a rede CBS por US\$ 5,4 bilhões; a Time Warner pagou US\$ 8,5 bilhões pela Turner Broadcasting Corporation, passando a ser o maior conglomerado de mídia e diversão do planeta; Rupert Murdoch, dono da News Corporation, incorporou a New World Communications à rede Fox, tornando-se o maior proprietário de emissoras de TV dos EUA; a gravadora britânica EMI desvinculou-se da Thorn, mas manteve a quinta colocação no mercado fonográfico. Antes, a Viacom havia comprado, por US $\$ 4$ bilhões, a Paramount Pictures.

Cada transação indica interpenetrações setoriais. A Disney obteve, com a Capital Cities/ABC, a cadeia de televisão que lhe faltava como suporte de exibição e de distribuição dos filmes, seriados e desenhos animados produzidos por seus estúdios. A Westinghouse, que em 1920 realizou a primeira emissão de rádio nos EUA, realizou a antiga ambição de agregar projetos de comunicação a seus domínios em eletrônica e geração de energias. Da noite para o dia, tomou conta de 12 emissoras de TV e 39 de rádio que cobrem um terço do território norte-americano. A Time Warner vinculou os canais da Turner à sua operadora de TV a cabo, incrementando as vendas de programas.

Segundo a Securities Data Company, as 11.123 fusões de empresas em 1997 somaram US\$ 913 bilhões, cifra já superada no primeiro semestre de 1998, que totalizou US\$1 trilhão, com média de 29 transações por dia. ${ }^{13}$ Os levantamentos da KPMG, da Broadwiew Associates e da Veronis, Suhler \& Associates Inc. apontaram a indústria de mídia como sexta área na preferência dos investidores norte-americanos em 1997 , com US $\$ 17,8$ bilhões movimentados em 525 transações (47\% a mais do que em 1996). Foi superada apenas por aplicações em bancos (US $\$ 34$ bilhões), energia elétrica (US\$ 30 bilhões), seguradoras (US\$ 24 bilhões), indústria químico-farmacêutica (US $\$ 22$ bilhões) e telecomunicações (US\$ 18 bilhões). "O setor de comunicação continuará a ser um dos mais quentes", garante o presidente da Broadview, Paul Deninger. "As companhias de mídia tradicional esforçam-se para conso- 
lidar suas posições e, simultaneamente, expandem-se na distribuição de conteúdos digitais. Aumentará a demanda por firmas especializadas em provimento de acesso à Internet e serviços on line ou por aquelas voltadas para o comércio eletrônico." 14

A consultoria Kaye Scholer estima que o número de redes nacionais de TV nos EUA cairá de cerca de 100 para 12. Com a desregulamentação de 1996, as cadeias nacionais de rádio diminuíram de 50 para 10, e segundo a Kaye Scholer podem se restringir a cinco no começo do próximo século. ${ }^{15}$ Pesquisa do jornal USA Today revela que, das 10.339 estações existentes no pais, 4.407 foram vendidas a partir de 1997, por um montante de US $\$ 32,4$ bilhões - quase todas absorvidas por conglomerados. ${ }^{16}$ Após a fusão com a Capstar Broadcasting, em agosto de 1998, a Chancellor Media tornou-se a maior rede de rádio do pais, com 463 emissoras entre Porto Rico e Los Angeles e 65 mithões de ouvintes. O maior acionista das duas empresas é o bilionário fundo de investimentos Hicks, Muse, Tate \& Furst, do Texas, detentor da maior cadeia de cinemas dos EUA. Nos últimos dez anos, o HMTF intermediou mais de 200 transações envolvendo meios de comunicação nas Américas do Norte e Latina, Europa e Ásia. ${ }^{17}$

\section{Os modelos de concentração}

$\mathrm{Na}$ atmosfera de concentração e reconcentração de ativos, as corporações entrelaçam a propriedade de cinemas (estúdios, produção, distribuição e exibição de filmes), gravadoras de discos, editoras, parques de diversões, TVs abertas e pagas, emissoras de rádio, revistas, jornais, serviços on line, provedores de acesso à Internet, videos, jogos, sofiwares e CD-ROMs. A sinergia entre troncos, unidades, redes e cadeias de uma mesma corporação revela-se crucial para reposicionamentos mercadológicos. notadamente numa conjuntura econômica marcada por altíssima taxa de inovação e expansão de conhecimento cientifico, e de renovação incessante de sistemas, métodos e produtos. ${ }^{18} \mathrm{~A}$ Disney, por exemplo, não apenas produz desenhos de longa-metragem com alta tecnologia de animação. como os conjuga a discos, videos. brinquedos, álbuns e publicações. São os chamados filmeseventos globais (O Rei Leão, Godzilla e Titanic, entre outros). Com O Rei Leão, a Disney faturou US\$ I bilhão em 1994, incluindo receitas de bilheteria, merchandising e comercialização de mercadorias agregados. O sucesso foi tamanho que a Disney, pela primeira vez em sua história. 
concordou em exibir um desenho animado de longa-metragem na televisão aberta (rede $A B C$ ).

O marketing das superempresas explora marcas e conteúdos de todos os modos possíveis. Vejamos o caso do seriado televisivo Arquivo- $X$, produzido pela Twentieh Century Fox e veiculado pela rede Fox, ambas pertencentes à News Corporation. Nos primeiros cinco anos de exibição, foi exportado para vários continentes e, em 1998, entrou em cartaz o primeiro longa-metragem inspirado em um dos episódios de maior sucesso. Outras unidades da News interferem para a multiplicação do $A r$ quivo-X. A Fox Interactive lançou dois jogos baseados na série; a Harper-Collins editou os livros; a Fox Music, a trilha sonora em CD; a Fox Home Video, os vídeos; e a Fox Licensing e Merchandising cuidou do licenciamento mundial do slogan do programa, "A verdade está lá fora". O resultado é um lucro fabuloso para a Twentieh Century: cada episódio custa US\$ 1 milhão e gera US\$ 3 milhões em receitas. Sem contar o faturamento específico das demais subsidiárias da News envolvidas. $^{19}$

Essas articulações alinham a indústria da comunicação aos setores mais dinâmicos do capitalismo, sob efetiva hegemonia dos EUA como pólo de produção e distribuição de conteúdos. As disparidades tecnológicas e os frágeis mecanismos de regulação dos fluxos internacionais de dados e imagens favorecem cada vez mais os megagrupos norte-americanos. Os programas audiovisuais (cinema e televisão) lideram as exportações dos EUA. Na Europa Ocidental, a cota de mercado para os filmes norte-americanos passou de 53\% em 1985 para 76\% em 1994 (ano em que os cinco filmes de maior bilheteria na França eram todos made in Hollywood). Mas somente $1 \%$ dos filmes exibidos nos EUA são europeus. Ainda em 1994, Hollywood respondia por 53\% das programações de 50 cadeias de TV aberta européias. ${ }^{20}$ A invasão audiovisual no Brasil pode ser medida pelo volume de filmes norteamericanos exibidos pelas TVs por assinatura. Em maio de 1998, a TVA, do grupo Abril, exibiu 865 filmes nos canais HBO, HBO2, Cinemax, TNT, Fox, MGM, Eurochannel, Warner, Sony e Bravo Brasil, dos quais 650 produzidos nos EUA - o que representa $75 \%$ do total. As películas européias somaram 153 (18\%), sendo 65 britânicos, 25 franceses, 18 espanhóis e 15 italianos. Ao cinema brasileiro coube a ínfima cota de 21 filmes (2,5\%). Nenhum outro país latino-americano entrou na seleção. ${ }^{21}$ 
Quatro modalidades de concentração caracterizam o atual estágio do mercado de midia: 1) horizontal: trata-se da monopolização ou oligopolização que se produz dentro de uma mesma área, como, por exemplo. o dominio da TV por assinatura por poucas operadoras; 2) vertical: diz respeito à integração das etapas de produção e distribuição, com um único grupo controlando desde os vários aspectos da elaboração de programas de televisão até a sua veiculação, comercialização e distribuição: 3) propriedade cruzada: propriedade simultânea, por conglomerados. de diferentes meios de comunicações (canais de TV por cabo, MMDS ou satélite, emissoras de rádio. revistas, jornais, provedores de Internet, telefonia celular); 4) monopólio em cruz: refere-se à reprodução, em nivel local e regional, dos oligopólios da "propriedade cruzada". Os quatro cenários conduzem à oligopolização, limitando drasticamente a concorrência naqueles setores que requerem dispêndios de monta e atualização tecnológica. 2

Observa-se com nitidez essa compressão na TV por assinatura via satélite (DTH): na maioria dos países, não mais do que três consórcios oferecem o serviço. Atuam nos EUA DirecTV, Primestar e Echostar; na América Latina, DirecTV e Sky; na Espanha, Vía Digital e Canal Satélite; na Alemanha, Premiere e DF1; no Canadá, ExpressVu e Star Choice. Presente em 30\% dos lares norte-americanos (contra $65 \%$ das redes a cabo), a TV via satélite está repartida entre pesos-pesados. Os sócios majoritários da DirecTV são Hughes e General Motors. A Primestar une Time Warner, TCI, Comcast, Cox Communications e MediaOne.

Raríssimas companhias intermediárias podem vislumbrar uma vaga no condomínio dos gigantes mediáticos. Uma delas é a DreamWorks SKG, criada em 1995 por Steven Spielberg, Jeffrey Katzenberg e David Geffen. Ela vem se expandindo como fornecedora de conteúdos multimidias de alta tecnologia. Organiza-se em quatro divisões: Interactive, de games, CD-ROMs e brinquedos eletrônicos; Home Video, que comercializa videos; Television, de shows para TV; e Pictures. Esta lançou em 1997 os filmes The peacemaker, Amistad e Mouse Hunt e em 1998 os seus primeiros desenhos animados longametragem. Além de parceria com a Microsoft em programas audiovisuais e jogos em CD-ROM, a Dream Works associou-se à Silicon Graphics em um estúdio de animação digital, e à IBM para desenvolver bancos on line de imagens. Tem contratos com a $\mathrm{ABC}$ (produção de 
programas) e a Time Warner (seriados para o Warner Channel e filmes para o HBO), e acordos de distribuição de filmes com a MCA/Universal. A sociedade com a Time Warner prevê investimentos de US\$ 1 biIhão em dez anos. ${ }^{23}$ Outro projeto arrojado é o GameWorks, joint venture com a Sega e a Universal Studios para a construção, em diversos paises, de megacentros de entretenimento high tech, baseados em jogos de terceira dimensão, simuladores e vídeos interativos. Já funcionam cinco unidades nos EUA. As duas primeiras no exterior serão abertas no Rio de Janeiro e São Paulo, em conjunto com a Multiplan. ${ }^{24}$

Na avaliação abalizada de Robert W. McChesney, professor e pesquisador da Universidade de Wiscosin, o mercado global de mídia gira em torno de cinco a oito conglomerados, "com uma ou duas dúzias de empresas consideravelmente grandes ocupando os segmentos regionais de mercado e tendo acordos operacionais com um ou mais gigantes". ${ }^{25}$ A previsão é idêntica à feita em 1989 pelo então presidente da Time Incorporated, Nick Nicolas, quando da fusão com a Warner Communications: até 2000 , de seis a oito megacompanhias controlariam a comunicação no planeta.

As dez primeiras no ranking de midia e entretenimento figuram entre as 500 maiores companhias do mundo, com receitas anuais entre US\$ 5 bilhões e US\$ 25 bilhões. Conforme McChesney, por ordem de faturamento no último biênio são: Time Warner (US\$24,9 bilhões), Disney (US\$ 24 bilhões), Bertelsmann (US\$ 15 bilhões), News Corporation (14 bilhões), Viacom (US\$ 13 bilhões), Sony (US\$ 9 bilhões, relativos às divisões de informação e diversão), TCI (US $\$ 8$ bilhões), Universal (US\$ 7,5 bilhões), Polygram (US\$ 5,5 bilhões) e NBC (US\$ 5,4 bilhões). Apenas três não estão baseadas nos EUA: a alemã Bertelsmann, a anglo-holandesa Polygram e a japonesa Sony.

A balança de forças vai alterar-se em 1999 com a emergência da Seagram como big player, a partir das aquisições da Universal e, recentemente, da Polygram. A holding canadense tomará da Viacom o quinto lugar no ranking, estimando-se em US\$13 bilhões as receitas de suas empresas de entretenimento (ainda possui $45 \%$ das ações da USA Network e $20 \%$ da operadora de TV por assinatura britânica BSkyB, majoritariamente controlada por Rupert Murdoch). A Polygram é a líder do segmento fonográfico, detendo $23 \%$ das vendas mundiais. No total, a Seagram controlará $25 \%$ da indústria da música, já que o selo Universal responde por $2 \%$ do mercado. A Seagram pretende combinar as ações 
da Polygram com as da Universal (TV, cinema, música. vídeo, serviços on line e parques temáticos), propiciando uma economia de US $\$ 300$ milhões nos próximos dois anos. A Polygram possui um estúdio cinematográfico que complementará o da Universal, sexto maior dos EUA.

Segundo a revista norte-americana Variety, com receita de US\$5,38 bilhões e lucro líquido de US\$541 milhões, as Organizações Globo tornaram-se, em 1997, o $12^{\circ}$ maior grupo de comunicação do planeta, pulando 12 posições em apenas um ano, já que, em 1996, fora classificada em $24^{\circ}$ lugar. A Globo situa-se à frente da CBS $\left(13^{\circ}\right)$, da NBC $\left(16^{\circ}\right)$, da mexicana Televisa $\left(34^{\circ}\right)$, do argentino Clarín $\left(36^{\circ}\right)$ e da venezuelana Cisneros $\left(47^{\circ}\right)$. A britânica EMI Music aparece na $11^{a}$ posição. Em termos de lucratividade, porém, as empresas da familia Marinho vêm atrás da NBC, que alcançou US\$1,025 bilhão. Variety não levou em consideração o fato relevante de que o faturamento indicado para o Globo corresponde a todas as suas empresas, e não apenas as que possui em informação e diversão. Nota-se o mesmo problema metodológico em relação ao Granada Group, sediado em Londres. Com receita de US\$ 6,7 bilhões, ficou em oitavo lugar no ranking. Ocorre que tal quantia inclui os setores de hotelaria, restaurantes turísticos e industriais. locação de serviços e mercado financeiro. A divisão de mídia do Granada movimentou cerca de US\$ 4 bilhões em 1997, o que o desloca para o terceiro escalão.

Nos últimos dez anos, graças a aquisições e fusões, Time Warner, Disney, Bertelsmann e News Corporation triplicaram de tamanho e a Viacom duplicou. ${ }^{26}$ Os planejamentos corporativos obedecem a estratégias semelhantes: a) ofensividade máxima nas guerras industrial e mercadológica em qualquer hemisfério; b) centralização decisória e tecnoprodutiva, conglomeração setorial e desterritorialização das unidades de consumo: c) dispersão transcontinental dos negócios, com ênfase na Europa e nos mercados emergentes da Ásia e da América Latina; d) investimentos maciços em tecnologias digitais que estimulem a convergência em infotelecomunicações; e) acordos e joint ventures de amplo espectro, inclusive com grupos regionais, visando à otimização comercial de programações, bens e serviços. Em suma, os mastodontes da difusão movem-se pela Terra a partir de um modelo de gestão que se vai consolidando como paradigma universal. e cuja voracidade por ganhos de capital não conhece qualquer limite. 


\section{Conclusão}

Os audaciosos movimentos dos complexos de mídia e entretenimento expressam uma monumental concentração de poder - tanto por controlarem dois terços do que se divulga no planeta, quanto pela aglomeração de atividades, patrimônios e ativos. Com alianças e fusões, a concorrência praticamente restringe-se ao clube de players, dotados de fortes reservas de capital, de know-how tecnológico e de capacidade de articular consórcios transoceânicos. Essas inversões afastam ainda mais empresas de menor porte e sedimenta uma industrialização em torno de blocos empresariais, que fazem das parcerias uma ferramenta para maximizar vantagens e lucros. Por conseguinte, a convergência tecnológica e de mundialização das informações se desdobra sob o signo da oligopolização de suportes e serviços - ainda que a retórica dos operadores insista na suposição dos benefícios imediatos e universais das novas safras tecnológicas.

À medida que tal configuração se cristaliza, reduz-se o campo de manobra para um desenvolvimento equilibrado e estável das redes de comunicação. Acentuam-se descompassos estruturais, no contexto da desnacionalização de áreas-chave. A concentração estreita as margens de pluralismo, na medida em que a conformação dos conteúdos obedece, de um lado, às injunções mercadológicas (aí incluídas determinadas sinalizações da audiência) e, de outro, às diretivas e às conveniências de seus controladores.

É forçoso reconhecer que a grande mídia disponibiliza dados e imagens que podem estreitar vínculos entre a sociedade, a política e a cultura. Mas os profundos desniveis entre países altamente industrializados, emergentes e subdesenvolvidos importam dependências e desigualdades no interior das redes mundiais, seja no intercâmbio de conteúdos ou nos acessos e usufrutos dos serviços. A começar pelo absurdo desequilibrio na balança comercial da indústria do audiovisual: o leão USA abocanha entre $65 \%$ e $80 \%$ das praças internacionais e importa cotas irrisórias de um círculo restrito de países.

No vácuo aberto pelas desregulamentações neoliberais e pelo isolamento da sociedade civil nos fóruns decisórios, os gigantes norte-americanos revalidam, sem atropelos, a sua descomunal hegemonia em amplas regiões do planeta. As unidades descentralizadas de produção aplicam sistemas, diretrizes, formatos e linguagens fixados pelas matrizes, sem perder de vista um dos princípios básicos da ofensiva internacional: 
globalização, regionalização e segmentação se entrelaçam e se suplementam (com tensões e ajustes permanentes). As corporações transnacionais põem em órbita valores essenciais da ideologia hegemônica, como o consumo desmedido, o mito da cultura sem fronteiras, o individualismo e a competição desenfreada.

$\mathrm{Na}$ contramão deste cenário inquietante, o compromisso com a mundialização da cidadania impõe manter os holofotes acesos sobre os impérios de midia. É vital insistir no estabelecimento de politicas democráticas de comunicação. Significa empenhar-se pela conquista permanente e cumulativa de espaços no interior da esfera pública, tanto na sociedade civil como no próprio Estado, no sentido de inverter progressivamente a correlação de forças. E assim redesenhar o estratégico campo comunicacional numa perspectiva pluralista e não-oligopolística.

\section{Notas}

1 Dick Parsons, citado por The Economist/Gazeta Mercantil, 18 de dezembro de 1998.

2 Lester Thurrow. O futuro do capitalismo: como as forças econômicas moldam o mundo de amanhã. $2^{a}$ ed. Rio: Rocco, 1997, p. 102.

"Heinz-Peter Elstrodt, citado por Eliana Simonetti, "Gigantes na pista", Veja, 13 de maio de 1998.

${ }^{4}$ Raj Sisodia, citado por Daniela Mendes, "Fusões bilionárias agitam o mundo", Correio Braziliense, 24 de maio de 1998.

5 René Armand Dreifuss. A época das perplexidades: mundialização, globalização e planetarização - novos desafios. Petrópolis: Vozes, 1996, p. 94-95.

${ }^{6}$ Ibidem, p. 118-119.

7 Philippe Nataf, citado em Media Report. EBN/GNT, 11 de fevereiro de 1998.

s Peter Kann, citado por Bloomberg Business News, 9 de dezembro de 1998.

"Gazeta Mercantil Latino-Americana, 6 a 12 de julho de 1998. A Motorola - uma das lideres mundiais em comunicação sem fio, semicondutores e sistemas eletrônicos avançados - anunciou, em junho de 1998. corte de 10\% em sua folha de pessoal. Quinze mil pessoas serão demitidas. como parte de um plano para economizar US\$750 mithões por ano. 
${ }^{10}$ Gazeta Mercantil, 11 de dezembro de 1998.

"Robert Kurz, "A orgia do capitalismo", Folha de S. Paulo (Mais!), 31 de maio de 1998.

12 Ver Marcial Murciano, "As politicas públicas de comunicação na Europa: uma análise a partir da perspectiva dos macroespaços regionais", em Revista Famecos: mídia, cultura e tecnologia, $\mathrm{n}^{\circ} 7$, novembro de 1997, p. 15.

${ }^{13}$ Alessandra Blanco, "Fusões nos EUA atingem US\$1 tri em 98", Folha de S. Paulo, 9 de agosto de 1998.

${ }^{14}$ Paul Deninger, citado em "Media sector shows strongest M\&A growth", disponível em 21 de janeiro de 1998 no site da Broadview Associates. Ver ainda: Vladimir Goitia, "Investimentos em fusões e aquisições crescem 21\%", O Estado de S. Paulo, 31 de janeiro de 1998; The Wall Street Journal, 7 de julho de 1998.

${ }^{15}$ Alessandra Blanco, "Fusões nos EUA atingem US\$ 1 tri em 98", Folha de S. Paulo, 9 de agosto de 1998.

${ }^{16}$ USA Today, 7 de julho de 1998.

${ }^{17}$ Elisa Araújo, "Gigantes americanos do rádio se unem em megarede", BlueBus, 28 de agosto de 1998.

${ }^{18}$ René Armand Dreifuss. A época das perplexidades, ob. cit., p. 46.

${ }^{19}$ The Economist/Gazeta Mercantil, 18 de dezembro de 1998.

${ }^{20}$ Ver Ignacio Ramonet. Un mundo sin rumbo, ob. cit, p. 59; Lester Thurow, O futuro do capitalismo, ob. cit, p. 176-177.

${ }^{21}$ Revista TVA, $\mathrm{n}^{\circ} 81$, maio de 1998. A partir de novembro de 1998, o cinema latino-americano começou a ganhar espaços nas TVs pagas. A Kushner Locke, empresa norte-americana de produção e distribuição de cinema independente, através de sua subsidiária Phoenix World Investments, baseada no Chile, tornará disponível às operadoras da América Latina o Gran Canal Latino, com um acervo inicial de mais de 400 longas produzidos na região. Luiz Moura, "Canal pago só de filmes latino-americanos", Meio e Mensagem, $1^{\circ}$ de agosto de 1998.

22 Ver Venício Artur de Lima, Perspectivas para as comunicações no Brasil do Século XXI: concentração de propriedade e redefinição dos atores politicos, Institute of Latin American Studies/University of Texas at Austin, novembro de 1997, disponivel em: http:// www.lanic.utexas.edu/ilas/brazctr/papers/veniciodelima.html.

23 Joseph Gelmis, "Spielberg extravasa paixão por games", Newsday/ O Estado de S. Paulo, 16 de janeiro de 1998. 
24 Mark Frauenfelder, "Spielberg plays prepares for GameWorks launch", Wired News, 27 de janeiro de 1997; O Estado de S. Paulo, 14 de maio de 1998.

is Robert W. McChesney, "The global struggle for democratic communication", Monthly Review, 1996. Ver ainda, do mesmo autor, The global media: the new missionaires of the corporate capitalism. Washington/Londres: Cassell, 1997, sobretudo o capítulo 3.

${ }^{26}$ Robert W. McChesney, "The global media giants: the nine firms that dominate the world", Extra - The magazine of fair, novembro/dezembro de 1997. 
